Veterinary Microbiology Volume 113, Issues 1-2, 10 March 2006, Pages 153-158

doi:10.1016/j.vetmic.2005.10.034

Copyright (c) 2005 Elsevier B.V. All rights reserved.

\title{
Distribution of Salmonella enterica Serovars from humans, livestock and meat in Vietnam and the Dominance of Salmonella Typhimurium Phage Type 90
}

\section{An.T.T. Vo ${ }^{a, d}$, Engeline van Duijkeren ${ }^{a}, *$ Ad C. Fluit ${ }^{b}$, Max E.O.C. Heck ${ }^{c}$, Anjo Verbruggen ${ }^{c}$, Henny M.E. Maas ${ }^{c}$ and Wim Gaastra ${ }^{a}$}

\author{
${ }^{a}$ Bacteriology Division, Department of Infectious Diseases and Immunology, \\ Faculty of Veterinary Medicine, Utrecht University, P.O. Box 80165, 3508 TD \\ Utrecht, The Netherlands \\ ${ }^{\mathrm{b}}$ Eijkman-Winkler Center, University Medical Center Utrecht \\ ${ }^{\mathrm{c}}$ National Institute of Public Health and the Environment, Bilthoven, The \\ Netherlands \\ ${ }^{\mathrm{d}}$ Faculty of Animal Science and Veterinary Medicine, Nong Lam University, \\ Vietnam
}

\begin{abstract}
Epidemiologically unrelated non-typhoid Salmonella isolates from humans $(n=56)$ and animal origin ( $n=241$, from faeces, carcasses and meat) in Vietnam were investigated. Salmonella Typhimurium, S. Anatum, S. Weltevreden, S. Emek, and S. Rissen were the most prevalent serovars. S. Typhimurium phage type 90 was predominant among $S$. Typhimurium isolates. The serotype and phage type distribution of the Salmonella isolates was different from that in Europe and America. Many sero- and phage types found in humans were also found in cattle, pigs, and poultry suggesting that food producing animals are an important source of human non-typhoid Salmonella infection in Vietnam.
\end{abstract}

\section{Introduction}

Non-typhoid Salmonella infections in humans continue to be a major problem, in terms of both morbidity and economic costs (Tirado and Schmidt, 2001). The majority of the 2500 Salmonella serovars are capable of causing infections in humans. Most human Salmonella outbreaks are associated with the consumption of contaminated products from animal origin (Wray and Wray, 2000) although non-foodborne Salmonella infection in humans may be transmitted during contact with animals, contaminated water, or the environment.

The widespread distribution of food is a global challenge in Salmonella control. With increasing travel and global trade, outbreaks involving widely scattered cases are occurring more frequently. Contaminated food produced in one country may cause illness in another, demonstrating the importance of national control programmes. Besides sero-typing, phage typing has played a central role in epidemiological studies in Salmonella Typhimurium and Salmonella Enteritidis (Anderson et al., 1977 and Ward et al., 1987).

The aim of this study was to examine the distribution of serovars and phage types among Salmonella strains isolated from humans, cattle, pigs and poultry in Vietnam in order to contribute to the understanding of the epidemiology of Salmonella. 


\section{Materials and methods}

\subsection{Bacterial isolates}

A total of 297 epidemiologically unrelated isolates were included in this study. The isolates were from humans $(n=56)$, cattle $(n=63)$, pigs $(n=111)$, and poultry $(n=67)$. The 56 clinical human isolates of unrelated patients with diarrhoea and fever were obtained from five provincial hospitals and two Pasteur Institutes in Vietnam.

\subsection{Sampling}

The animal isolates were collected from pigs, cattle, chickens and ducks (Table 1) in 13 provinces of South Vietnam during the year 2004. Faecal samples from healthy animals were taken at the slaughterhouses (78\%) and from healthy or sick animals on farms (12\%). The animals sampled came from different flocks or herds. For poultry, only samples from healthy animals were collected due to the risk of avian flu infection during the study period. Rectal faecal samples were taken from pigs and cattle. Faecal samples from poultry were taken from the distal part of the intestinal tract in the slaughterhouses or from pooled samples from 5 to 10 animals on the farms. About $25 \mathrm{~g}$ of faeces was collected from each animal (except for poultry on the farms) and placed in a sterile sampling bag, kept in an ice-box at $4{ }^{\circ} \mathrm{C}$ and transported to the diagnostic laboratories within $24 \mathrm{~h}$. For carcass and meat samples, a carcass-swabbing method using cotton surgical gauzes $(10 \mathrm{~cm} \times 20 \mathrm{~cm} \times 5 \mathrm{~mm})$ was applied to the whole carcasses of poultry, pigs or cattle in the slaughterhouses. No carcass samples were taken from animals from which rectal faecal samples were collected. Approximately $25 \mathrm{~g}$ of minced meat or cut meat was sampled in supermarkets, markets or restaurants and transported to the laboratory in the same conditions described for faecal samples. Five to 20 samples were taken at each animal farm, slaughterhouse, market or restaurant. Samples were analysed at Nong Lam University laboratories and two laboratories of the Provincial Departments of Animal Health of Vietnam.

Table 1.

Origins of the investigated Salmonella isolates

\begin{tabular}{|l|l|l|l|l|l|l|}
\hline & $\begin{array}{l}\text { No. samples } \\
\text { taken }\end{array}$ & $\begin{array}{l}\text { No. positive } \\
(\%)\end{array}$ & \multicolumn{4}{l|}{ No. investigated isolates } \\
\hline & & & $\begin{array}{l}\text { From } \\
\text { faeces }\end{array}$ & $\begin{array}{l}\text { From } \\
\text { carcasses }\end{array}$ & $\begin{array}{l}\text { From } \\
\text { meat }\end{array}$ & Total \\
\hline Pigs & 534 & $264(49.4)$ & $77\left(14^{\mathrm{a}}\right)$ & 23 & 11 & 111 \\
\hline Cattle & 390 & $107(27.4)$ & $37\left(16^{\mathrm{a}}\right)$ & 16 & 10 & 63 \\
\hline Chicken & 257 & $99(38.5)$ & 18 & 35 & 11 & 64 \\
\hline Ducks & 34 & $7(20.5)$ & 3 & 0 & 0 & 3 \\
\hline
\end{tabular}

${ }^{a}$ Isolates from animals with diarrhoea. 


\subsection{Salmonella isolation}

The bacterial culture procedure was carried out as described in standard ISO6579 (International Organization for Standardization, 1993). Briefly, faecal or meat samples were mixed with Buffer Peptone Water (BPW) at a 1:9 ratio, using a stomacher for $1 \mathrm{~min}$ and incubated at $37^{\circ} \mathrm{C}$ for $18-24 \mathrm{~h}$. Then, 1 and $0.1 \mathrm{ml}$ of the culture was transferred to $10 \mathrm{ml}$ of Müller-Kauffmann Tetrathionate Broth (MKTT) and $10 \mathrm{ml}$ of Rappaport Vassiliadis Soya Broth (RVS), respectively, and incubated at $42^{\circ} \mathrm{C}$ for $24-48 \mathrm{~h}$. The culture was then streaked onto Xylose Lysine Decarboxylase Agar (XLD) and Brilliant Green Agar (BGA). Colonies suspected of being Salmonella were transferred to Nutrient Agar plates and were biochemically characterized using Triple Sugar Iron Agar (TSI), Lysine Decarboxylase Broth (LDC), Urea Agar, and Tryptone Broth. All media (except Lysine Decarboxylase Broth supplied by Merck) were purchased from Oxoid (UK). If more than one sample from a slaughterhouse, farm, market or supermarket was Salmonella positive, only one isolate was randomly chosen and included in this study.

\subsection{Sero typing and phage typing}

Salmonella isolates were serotyped by slide and microtitre agglutination for $\mathrm{O}$ and $\mathrm{H}$ antigen (the antisera were purchased from Statens Serum Institut, Denmark) according to the latest version of the Kauffmann and White scheme (Popoff, 2001) at the Diagnostic Labotarory for Infectious Diseases and Perinatal Screening of the Dutch National Institute of Public Health and the Environment (RIVM).

Bacteriophage typing was used for $S$. Typhimurium and S. Enteritidis. The pattern of lysis produced by infection with typing phages was recorded and designated in accordance with the standard schemes. UT indicates untypeable, which means that a tested isolate was not lysed by any of the typing phages. RDNC indicates that the isolate reacted with some of the typing phages but did not conform to any recognized phage type in the typing scheme. S. Typhimurium phage types were determined using the method described by Anderson et al. (1977) and the interpretive guidelines supplied by the Public Health Laboratory Service (PHLS) in Colindale, United Kingdom. In addition, the Dutch phage typing system was also used (Guinee et al., 1974). Salmonella Enteritidis isolates were phage typed using the English phage typing system as described by Ward et al. (1987).

\section{Results}

The percentage of Salmonella-positive samples was 20.5, 27.4, 38.5 and $49.4 \%$ for duck, cattle, chicken and pig samples, respectively (Table 1 ). We found 38 serovars among the 297 Salmonella isolates originating from humans and animals. The 10 most common serovars represented approximately $79 \%$ of the collection (Table 2 ). The predominant serovars (S. Typhimurium, $S$. Anatum, $S$. Weltevreden, S. Emek, and S. Rissen) accounted for about $59 \%$ of the isolates. The distribution of Salmonella serovars among the different sources is shown in Table 2. S. Typhimurium (37.5\%) was the most common serovar among the 56 Salmonella isolates from humans, followed by $S$. Enteritidis $(12.5 \%)$ and $S$. Weltevreden (7.1\%). In cattle, serovar Anatum, Weltevreden and Lexington were predominant and represented 23.8, 17.5 and $15.8 \%$, of the 63 bovine isolates, respectively. Among the 111 porcine isolates, S. Anatum (26.1\%) and S. Typhimurium (20.7\%) were the most common serovars, followed by $S$. Weltevreden (15.3\%), S. Derby (11.7\%) and S. Rissen $(11.7 \%)$. S. Emek $(38.8 \%)$ and S. Blockley $(20.9 \%)$ were the most prevalent serovars among 67 isolates originating from poultry. The distribution of Salmonella Typhimurium 
phage types is shown in Table 3. Of the $47 \mathrm{~S}$. Typhimurium isolates, the Dutch phage type (pt) 90 was predominant and accounted for $57.5 \%$ of all $S$.

Typhimurium isolates from humans, pigs and cattle. These 27 isolates could not be typed with the English phage typing system (see Table 3). S. Typhimurium RDNC accounted for nearly $20 \%$ of the phage types of this serovar (by the Dutch system). The Dutch phage type 506 (corresponding with DT 104 in the English phage typing system) was found at a low rate (4.3\%). Among the $S$. Enteritidis isolates, two phage types were found, pt $1(n=1)$ and pt $7(n=2)$. Four isolates did not react with any of the phages used.

Table 2.

Distribution of the most common Salmonella serovars isolated in Vietnam from humans, cattle, pigs and poultry

\begin{tabular}{|c|c|c|c|c|c|}
\hline Salmonella serovars & Humans & Cattle $\left({ }^{a}\right)$ & Pigs $\left({ }^{a}\right)$ & Poultry & Total (\%) \\
\hline Typhimurium & 21 & 3 & $23\left(3^{a}\right)$ & & $47(15.8)$ \\
\hline Anatum & 1 & $15\left(7^{\mathrm{a}}\right)$ & $29\left(4^{a}\right)$ & 1 & $46(15.5)$ \\
\hline Weltevreden & 4 & $11\left(2^{\mathrm{a}}\right)$ & $17\left(3^{a}\right)$ & 2 & $34(11.4)$ \\
\hline Emek & 2 & & & 26 & $28(9.4)$ \\
\hline Rissen & & 5 & 13 & 1 & $19(6.4)$ \\
\hline Derby & & $3\left(1^{a}\right)$ & $13\left(1^{\mathrm{a}}\right)$ & 1 & $17(5.7)$ \\
\hline Blockley & 1 & & & 14 & $15(5.1)$ \\
\hline S. (I), 4, 5, 12: b, - & 2 & 3 & $4\left(2^{a}\right)$ & 1 & $10(3.4)$ \\
\hline Lexington & & $10\left(1^{\mathrm{a}}\right)$ & & & $10(3.4)$ \\
\hline Hadar & 2 & & & 6 & $8(2.7)$ \\
\hline Newport & 1 & 1 & 6 & 0 & $8(2.7)$ \\
\hline London & & 1 & 2 & 4 & $7(2.4)$ \\
\hline Enteritidis & 7 & & & & $7(2.4)$ \\
\hline Albany & 1 & & & 3 & $4(1.3)$ \\
\hline Panama & 1 & & 2 & & $3(1.0)$ \\
\hline Rubislaw & & $3\left(3^{\mathrm{a}}\right)$ & & & $3(1.0)$ \\
\hline Kedougou & 2 & & & & $2(0.7)$ \\
\hline Schwarzengrund & & & & 2 & $2(0.7)$ \\
\hline Tallahassee & & & & 2 & $2(0.7)$ \\
\hline Others & 11 & $8\left(2^{\mathrm{a}}\right)$ & $2\left(1^{a}\right)$ & 4 & $25(8.3)$ \\
\hline Total & 56 & 63 & 111 & 67 & 297 \\
\hline
\end{tabular}

${ }^{a}$ Isolates from animals with diarrhoea. 
Table 3.

Distribution of Salmonella Typhimurium phage types

\begin{tabular}{|c|c|c|c|}
\hline No. of isolates & Source & English phagetype & Dutch phagetype \\
\hline 9 & Human & $\mathrm{UT}^{\mathrm{a}}$ & 90 \\
\hline 2 & Cattle & UT & 90 \\
\hline 16 & Pig & UT & 90 \\
\hline 1 & Cattle & UT & 510 \\
\hline 1 & Pig & UT & 508 \\
\hline 2 & Pig & UT & 507 \\
\hline 1 & Human & UT & RDNC $^{b}$ \\
\hline 1 & Human & UT & UT \\
\hline 1 & Pig & UT & UT \\
\hline 1 & Human & 104 & 506 \\
\hline 1 & Pig & 104 & 506 \\
\hline 1 & Human & U302 & 507 \\
\hline 2 & Human & U302 & RDNC \\
\hline 1 & Pig & U302 & RDNC \\
\hline 1 & Human & 195 & 507 \\
\hline 1 & Human & 20 & RDNC \\
\hline 2 & Human & 12 & RDNC \\
\hline 2 & Human & RDNC & RDNC \\
\hline 1 & Pig & RDNC & RDNC \\
\hline
\end{tabular}

${ }^{\text {a }}$ UT untypeable.

${ }^{\mathrm{b}}$ RDNC reaction does not conform to any recognized phage types.

\section{Discussion}

Surveillance of Salmonella serovars and phage-types from human and animal sources is relevant for detecting national and global outbreaks, for identifying the source of an infection and for implementing prevention and control measures since the distribution of Salmonella serovars may differ between countries. To our knowledge, this is the first study comparing the serotypes and phage types of human Salmonella isolates to those of farm animals in Vietnam. We observed that $S$. Typhimurium, S. Anatum, S. Weltevreden, and S. Emek were the most common serovars in South Vietnam. S. Typhimurium was the most prevalent serovar in isolates of human origin. Pigs can be considered an important reservoir of $S$. Typhimurium since this serovar was frequently isolated from pig faeces and pork. S. Anatum and $S$. Weltevreden were isolated from humans, cattle, pigs and chickens. A similar finding was reported from Thailand (Bangtrakulnonth et al., 2004). While S. Typhimurium and S. Dublin are known to be predominant among 
isolates from cattle in Europe, Australia and America (Wray and Wray, 2000 and van Duijkeren et al., 2002) we found S. Anatum, S. Weltevreden and S. Lexington to be the most prevalent bovine Salmonella serovars in Vietnam. Among poultry isolates, S. Emek and S. Blockley predominated. S. Enteritidis was not cultured from poultry, although $S$. Enteritidis was often isolated from humans in Vietnam. In contrast, $S$. Enteritidis is frequently isolated from poultry in many European countries and in the USA and this animal species is an important source for human S. Enteritidis infections in these countries (Wray and Wray, 2000 and van Duijkeren et al., 2002). Our findings are in accordance with those of Tran et al. (2004) who conducted an investigation of Salmonella spp in pigs, chickens and ducks in Mekong delta provinces. They found only one $S$. Enteritidis isolate among 80 animal isolates. Thus, human $S$. Enteritidis infections in Vietnam probably originate from other sources. Another explanation for the low prevalence of $S$. Enteritidis in the present study might be that $95 \%$ of the poultry samples were taken from broilers due to the restricted access of poultry farms during the bird flu outbreak. Therefore only a small number of laying hens were sampled. The percentage of Salmonella positive samples in our study is much higher than the $7.1 \%$ reported by Tran et al. (2004). One possible explanation is the difference in the amount of sample used for culturing in their study, which was $1 \mathrm{~g}$, whereas in our study $25 \mathrm{~g}$ was sampled. Overall, the data from the present study indicate that the distribution of Salmonella serovars in Vietnam was similar to that of other South-East Asian countries (Bangtrakulnonth et al., 2004; WHO Global Salm-Surv, 2005) but different from that of European countries and the USA (Wray and Wray, 2000, van Duijkeren et al., 2002 and Pasquali et al., 2004). One possible reason for this are the differences in animal husbandry between the continents. Determination of the distribution of Salmonella serovars is important in the epidemiology of salmonellosis. It provides evidence of possible sources of food borne infection in a climate of increasing international travel and trade in food products of animal origin and may lead to improved prevention and control measures.

The Dutch pt 90 was the most common phage type among the $S$. Typhimurium isolates in Vietnam and was found among bovine, porcine and human $S$. Typhimurium isolates. The dominance of this phage type is considerably different from that in European countries and America where DT 104 (corresponding to pt 506 in the Dutch phage typing system) has been common among S. Typhimurium isolates. The Dutch phage typing system performed better in typing our Vietnamese $S$. Typhimurium isolates than the English phage typing system (Table 3 ). Seventy-four percent of the $S$. Typhimurium isolates could be phage-typed with the Dutch typing system compared to $21 \%$ in the English typing system. It is important to note that although the English phage typing method was able to type most of the $S$. Typhimurium isolates from European countries and the United State of America (van Duijkeren et al., 2002, Gebreyes et al., 2004 and Pasquali et al., 2004), this system could not type $77 \%(10 / 13)$ of Turkish S. Typhimurium isolates (Ang-Kucuker et al., 2000) and 12.2\% (27/221) of Japanese S. Typhimurium isolates (Izumiya et al., 2001).

In conclusion, the distribution of Salmonella serovars and phage types in Vietnam is considerably different from that in Europe and America. The same serotypes and phage types were found in humans and food animals with the exception of $S$. Enteritidis, which would suggest that farm animals are an important source of human non-typhoid Salmonella infection in Vietnam. 


\section{Acknowledgments}

This study was funded by a grant of the Vietnamese government to Project 322 of the Ministry of Education and Training. We appreciate the help of Associate Prof. Nguyen Ngoc Tuan, Dr. Nguyen Nhu Pho, Le Huu Ngoc, Van Thien Bao, Huynh Van Diem, Nguyen Kim Hoang, and physicians, veterinarians and technicians who assisted in the sampling procedures and isolation of Salmonella. We thank Dr. Nancy Bleumink and Carolien Flemming of Utrecht University, The Netherlands for assistance and technical guidance. We are grateful to Linda Ward and the staff of the Public Health Laboratory Service (PHLS) in Colindale, United Kingdom for providing the $S$. Typhimurium phages. 


\section{References}

Anderson et al., 1977 E.S. Anderson, L.R. Ward, M.J. Saxe and J.D. de Sa, Bacteriophage-typing designations of Salmonela typhimurium, J. Hyg. (Lond) 78 (1977), pp. 297-300.

Ang-Kucuker et al., 2000 M. Ang-Kucuker, V. Tolun, R. Helmuth, W. Rabsch, O. Buyukbaba-Boral, D. Torumkuney-Akbulut, S. Susever and O. Ang, Phage types, antibiotic susceptibilities and plasmid profiles of Salmonella Typhimurium and Salmonella Enteritidis strains isolated in Istanbul, Turkey Clin. Microbiol. Infect. 6 (2000), pp. 593-599.

Bangtrakulnonth et al., 2004 A. Bangtrakulnonth, S. Pornreongwong, C. Pulsrikarn, P. Sawanpanyalert, R.S. Hendriksen, D.M. Lo Fo Wong and F.M. Aarestrup, Salmonella serovars from humans and other sources in Thailand, 1993-2002, Emerg. Infect. Dis. 10 (2004), pp. 131-136.

Gebreyes et al., 2004 W.A. Gebreyes, S. Thakur, P.R. Davies, J.A. Funk and C. Altier, Trends in antimicrobial resistance, phage types and integrons among Salmonella serotypes from pigs, 19972000, J. Antimicrob. Chemother. 53 (2004), pp. 997-1003.

Guinee et al., 1974 P.A. Guinee, W.J. van Leeuwen and D. Pruys, Phage typing of S. Typhimurium in The Netherlands. 1. The phage typing system, Zentralbl. Bakteriol. 226 (1974), pp. 194-200.

International Organization for Standardization, 1993 International Organization for Standardization, 1993. ISO 6579- Microbiology-General Guidance on Methods for Detection of Salmonella, third ed. International Organization for Standardization, Geneva, Switzerland.

Izumiya et al., $2001 \mathrm{H}$. Izumiya, J. Terajima, S. Matsushita, K. Tamura and H. Watanabe, Characterization of multidrug-resistant Salmonella enterica serovar Typhimurium isolated in Japan, $\mathrm{J}$. Clin. Microbiol. 39 (2001), pp. 2700-2703.

Pasquali et al., 2004 F. Pasquali, A. de Cesare, A. Ricci, C. Kehrenberg, S. Schwarz and G. Manfreda, Phage types, ribotypes and tetracycline resistance genes of Salmonella enterica subsp. enterica serovar Typhimurium strains isolated from difference origins in Italy, Vet. Microbiol. 103 (2004), pp. 71-76.

Popoff, 2001 M.Y. Popoff, Antigenic formulas of the Salmonella serovars (eighth ed.), WHO Collaborating Center for Reference and Research on Salmonella, Paris, France (2001).

Tirado and Schmidt, 2001 C. Tirado and K. Schmidt, WHO surveillance programme for control of foodborne infections and intoxications: preliminary results and trends across greater Europe. World Health Organization, J. Infect. 43 (2001), pp. 80-84.

Tran et al., 2004 T.P. Tran, T.L.K. Ly, T.T. Nguyen, M. Akiba, N. Ogasawara, D. Shinoda, T.A. Okatani and H. Hayashidani, Prevalence of Salmonella spp. in pigs, chickens and ducks in the Mekong Delta, Vietnam, J. Vet. Med. Sci. 66 (2004), pp. 1011-1014.

van Duijkeren et al., 2002 E. van Duijkeren, W.J. Wannet, D.J. Houwers and W. van Pelt, Serotype and phage type distribution of Salmonella strains isolated from humans, cattle, pigs, and chickens in The Netherlands from 1984 to 2001, J. Clin. Microbiol. 40 (2002), pp. 3980-3985.

Ward et al., 1987 L.R. Ward, J.D. de Sa and B. Rowe, A phage-typing scheme for Salmonella Enteritidis, Epidemiol. Infect. 99 (1987), pp. 291-294.

Global Salm-Surv, 2005 WHO Global Salm-Surv, 2005. Top 15 Salmonella serotype list from each country (23 March 2005). http://thor.dfvf.dk/pls/portal/GSS.COUNTRY_DATA_SET_REP.show.

Wray and Wray, 2000 C. Wray and A. Wray, Salmonella in Domestic Animals, CABI Publishing, New York, USA (2000). 